\title{
TRANSPARENCY AND ACCOUNTABILITY IN URBAN PUBLIC PROCUREMENT: DESIGN OF A SELF-SOVEREIGN BLOCKCHAIN APP
}

\author{
Ana Balan 1,2, *, Sînică Alboaie 1,3,4, Karima Kourtit 4, 5, 6,7, Peter Nijkamp 4, 5, 6,7 \\ ${ }^{1}$ RomSoft SRL, Iași, România - ana.balan.m@gmail.com \\ ${ }^{2}$ Additech FIT SRL, Iaşi, România \\ ${ }^{3}$ Axiologic Research SRL, Iași, România - salboaie@ gmail.com \\ ${ }^{4}$ Alexandru Ioan Cuza University of Iași, Iași, România \\ ${ }^{5}$ Open University, Heerlen, the Netherlands - k_kourtit@hotmail.com \\ ${ }^{6}$ Polytechnic University, Ben Guerir, Morocco \\ ${ }^{7}$ Adam Mickiewicz University, Poznan, Poland - pnijkamp@ hotmail.com
}

\section{Commission IV}

KEY WORDS: Self-sovereignty, Smart city, Blockchain, Urban Public Procurement, Tendering Systems, Corruption

\begin{abstract}
:
This paper positions blockchain systems in the context of smart city policy. It argues that blockchain technology may be an effective vehicle in coping with corruption and 'false playing' in urban public procurement and tendering systems. It presents the design of new app (Self-Sovereign App or SSApp) to avoid corruptive behavior of agents.
\end{abstract}

\section{SMART CITIES IN THE DIGITAL ERA}

In recent years, the notion of smart or intelligent cities has attracted much interest, ranging from academic and policy circles to industry and ICT sectors. In the New Urban World (Kourtit, 2019), cities and urban agglomerations have turned into both powerful political and economic entities (called 'urban empires'; see (Glaeser, 2020)). Smart cities are inspired by the potential of modern digital technology and aim to obtain a significant increase in their performance (e.g., growth, jobs, environmental quality, health, safety and security) by using a well-orchestrated package of policy stimuli mainly based on internet technology (see, e.g., (Komninos, 2014); (Batty, 2018)).

Smart cities use the fruits of digital technologies in many ways, but in all cases a wealth of digital data (often including 'big data') is playing a key role (see (Kourtit, 2020)). Consequently, data analytics is a core knowledge-based activity in any smart city initiative. But it is also worth noting that hard core digital technology alone does not ensure the rise of a smart (i.e. sustainable, inclusive and safe) city (for a broad overview, (see (Komninos, 2019)). As argued (Ozdemir, 2019), digital technology is only a technical tool to achieve higher strategic goals, such as social equity, human health, individual and group satisfaction, job opportunities, etc. To achieve such goals necessitates advanced digital technology expertise, openminded and competent professionals, appropriate and goaloriented institutions, and rational information process management.

Smart cities are cities in evolution, depending on the intelligent use of, and adaptation to, the societal potential of digital technology systems. But smart cities are also externally influenced by the rapidly changing digital and technological environment to which they are exposed. That holds both for the use of advanced data metrics in multi-actor urban policy and city management, and for the application of new digital technology systems (such as artificial intelligence, machine learning and, more recently, blockchain technology systems) in modern multi-layered smart cities.

The present paper aims to provide an overview of the functionalities of new digital technology systems, in particular, blockchain technology, in the context of smart city policy. After a review of the nature of blockchains and their functioning in smart cities, we address the domain of corruption and bribery in public (or private-public) procurement systems in cities. We argue that blockchain technology may provide an effective mechanism for coping with false playing in public tendering procedures. We illustrate our arguments by sketching out the design of a new app (Self-sovereign App or SSApp) that has been built to effectively cope with corruption in modern smart cities.

\section{BLOCKCHAIN TECHNOLOGY IN A SMART CONTEXT: SETTING THE SCENE}

The concept of smart cities has been rapidly developing in recent years. Clearly, there is an ongoing trend towards more digitalisation, electronic service provision, e-democracy and citizen engagement, big data analytics, artificial intelligence, digital platforms, local sharing economies, and trends towards a prosumer society (see e.g. (Ritzen, 2010)). This trend can be illustrated by the rapid penetration of digital platforms, such as TripAdvisor, Airbnb, or Uber. Such pervasive digital systems, supported by the internet, may exert a far-reaching impact on decision making in - and on the functioning of - modern cities and industries. Large agglomerations tend to become data factories producing a wealth of heterogeneous and disconnected data systems.

We start with the following quotations: "The definition of the Smart City is still a confused and ambiguous concept. Even now, a Smart City is conceived as an idealistic city, where the quality of life for citizens is significantly improved by 
combining ICT, new services and new urban infrastructures. The main innovation in the Smart City evolutionary process consists of considering a user-centric vision, and accounting urban issues from the perspective of the citizens' needs, by engaging the citizens in the city management. In other words, the Smart City concept may be defined as an integrated system in which human and social capital heavily interact, using technology-based solutions. The application of the Internet of Things (IoT) paradigm to urban scenarios is of special interest to support the smart city vision. This vision aims to efficiently achieve sustainable and resilient development and a high quality of life on the basis of a multi-stakeholder, municipality-based partnership." See (Pieroni, 2018). It is also noted that: "Nowadays, cities face complex challenges to improve their citizens' quality of life. According to the 2014 United Nations (UN) World Urbanization Prospects report (United Nations, 2014), more than half of the global population now lives in urban areas, and an additional 2.5 billion people are predicted to move to cities by 2050. Due to urban concentration, people's living conditions have been impacted by an increase in traffic jams, carbon dioxide, greenhouse gas emissions," transmission of infectious diseases, "and waste disposal. The notion of the "smart city" is a response to these problems and has gained much popularity in the past decade. Many cities define themselves as "smart" when they identify some of their own characteristics as being so (such as broadband connectivity, digital inclusion, and a knowledge workforce). A common underlying fact is that these smart cities benefit from innovative applications of new kinds of information and communications technology (ICT) to support communal sharing (Agyeman and McLaren 2014). In the literature, the smart city is a broad idea that includes many aspects of urban life (Chourabi et al. 2012) and is also a fuzzy concept that has been used in ways that are not always compatible with each other (Cocchia 2014). The notion embraces several different dimensions depending on the meaning attributed to the word "smart" and the label "smart city." Some examples include the digital city (Couclelis 2004), the intelligent city (Komninos 2006), the knowledge city (Ergazakis et al. 2004), and the ubiquitous city (Anthopoulos and Fitsilis 2010). The ambiguity of the concept causes difficulty in understanding how information technology (IT) adoption impacts the development of smart cities development (Komninos et al. 2013)." See also (Sun, 2016).

There is a need for more coherent handling of the wealth of digital data. In this regard, blockchain systems may play a strategic and integrating role. Blockchains are integrated digital technology systems which require for an effective functioning a strict consistent design and proper management in order to become useful decision support tools for industry and government. Blockchain governance has two meanings in a city context:

1. the governance of data, which is the base of a blockchain structure; the focus is on decentralised data, while each user has a copy of the data, which eliminates a source of failure from a centralised system;

2. governance rules, decided by a consortium of stakeholders inside the blockchain in order to manage collected data, which depend on their applicability (i.e., data systems, governance) and which call for specific smart contracts based on the application that could automate some transactions.

By its very structure, blockchain technology allows a new type of collaboration at a large scale by automated trustless transactions. This is realised through a specific governance of data which should be decentralised, in order to eliminate the risks inherent in a single point of failure of a central body, to be transparent, and to thereby eliminate intermediation. This is all in the nature of a blockchain. Now, based on the applicability of a blockchain, by writing the handling rules into a blockchain, one can create effective ways of governance in different environments.

In the context of smart cities, blockchain technology is becoming increasingly important. Smart cities rely on data and the professional management of data. To make a city smart and functional, it is necessary to organise the data related to the city, and create rules based on that data, by managing and extracting valuable information for the satisfactory functioning of the city. Since, at the base of blockchain systems, there are some rules of governance that bring valuable benefits, the challenge is to write the rules of smart cities in the blockchain system. In this paper, this issue will now be handled in the context of procurement and tendering procedures in smart city policy. This issue will be introduced and discussed in Section 3.

\section{CITIES AND PROCUREMENT CORRUPTION}

Cities are complex interactive systems driven by individual and group motives, self-centered and collective interests and behaviours of actors, and governance agencies, political bodies and institutions. Cities comprise sub-systems at different scales (see Kourtit and Nijkamp 2019); they are essentially interdependent spatial systems in networks of interconnected cities. The rational governance and management of such complex city systems is fraught with difficulties of various nature. But in any case, smart city ruling should be guided by transparent guidelines which apply to everyone. Consequently, a clear, transparent and equally accessible playing field is a sine qua non for any sustainable city policy. Rational city governance is at odds with privileged treatment, collusion, extortion, false information, corruption or bribery.

The conditions under which corruption can emerge are different; there is individual misbehaviour in corruption and there is institutionalized corruption. In a recent article by Korosteleva et al. (2020) a thorough empirical analysis of corruptive behaviour in different European cities is carried out. City size and more capital cities appear to important factors for a relative over-presence of bribery.

To illustrate the seriousness of public procurement corruption and the need to effectively cope with this undesirable phenomenon, we present a few cited from a corruption watch website (Pillay et al. 2015).

"A tender is an offer to do work or supply goods at a fixed price. When the government puts out a tender, this means that it asks the public for price offers to do work or supply goods. Once the government accepts a tender, it is binding to both the government and the winning tenderer. Therefore, the person or company has to provide the goods or services in the manner agreed to and at the price offered; and the government must pay the agreed price at the agreed time.

A business must first ensure that it is registered on the supplier database of the relevant local, provincial or national authority this is a requirement for tender consideration, and the government may go to these suppliers directly for smaller tenders. It must have a bank account and be registered with the South African Revenue Services. To get registered, a 
businessperson can contact the government entity involved, which will ensure that he or she gets the right form as they may vary slightly. Forms must be accompanied by supporting documentation, such as a company registration certificate, a BEE certificate or a tax clearance certificate. All requested information, such as the shareholders of the company, the regions in which it operates, and its previous supply chain management experience must be disclosed - but the information will remain confidential. Once a business has registered, it is ready to bid for tenders.".

"Because the procedures involved are complex, corruption may occur at any point along the way.”.

"Procurement corruption has many forms. There are a number of ways in which corruption occurs in public procurement. They include: Bribery - seen as the most common type of corruption, it can be understood as an offer of money, goods or services in order to gain an advantage. Bribes can be used to avoid red tape, speed up procedures and influence the allocation of tenders. Active bribery refers to the offence committed by the person who promises or gives the bribe, while passive bribery is the offence committed by the official who receives the bribe. Active bribery occurs on the supply side, passive bribery on the demand side.".

"Transparency is the quality of being clear, honest and open. It implies that civil servants have a duty to act visibly, predictably and understandably. Transparency requires that decisions and actions are taken openly, and that sufficient information is available so that other agencies and the general public can assess whether the relevant procedures are followed. Whistleblower - can be defined as an employee, former employee, or member of an organisation who reports misconduct to people or entities that are able to take corrective action.”.

Now the question is whether modern digital technology - in particular blockchain technology - may be an effective systemic vehicle in coping with corruption in the public sector. In the present paper we will focus the attention in particular on procurement procedures in cities (e.g., infrastructure, housing programmes, cultural amenities, concessions etc.), which often concern large sums of money. Corruption distorts markets and creates unfair competition. Companies often pay bribes or rig bids to win public procurement contracts. Many companies hide corrupt acts behind secret subsidiaries and partnerships. Or they seek to influence political decision-making illicitly. Others exploit tax laws, construct cartels or abuse legal loopholes. Private companies have huge influence in many public spheres, which are often crucial - from energy to healthcare. So, it's easy to see how corruption in business harms taxpayers' interests. See (Transparency International, 2020). Corruption does not only show up in underdeveloped areas but is present everywhere in the public sector. A recent survey "presents the direct cost of corruption in public procurement in different sectors of economy in 8 EU Member States: France, Hungary, Italy, Lithuania, the Netherlands, Poland, Romania and Spain. The probability of corrupt cases is given in percentages and is going from a minimum of $10-11 \%$ to a maximum of $33-37 \%$. The highest percentage of direct public loss due to corruption as percentage of the volume is $43 \%$ reached in training and staff development services. In fiat currency the highest estimation of loss due to corruption is found in the sector of urban/utility construction and is estimated between 830 to 1141 million euros". See (Wensink et al. 2013). We will ask in the present paper the question whether blockchain systems can act as a countervailing power against bribery.
It is evident that in a procurement procedure a fair tendering is needed. In the EU public procurement process, a standard data portal (SIMAP) is often used, which offers transparent and direct access to public information. It is noteworthy that the official approaches to fair tendering are based on centralized tender management systems that are characterized by standard market criteria (e.g. trust, transparency, confidence, accountability etc.), so that all relevant information can be checked and controlled. Nevertheless, corruptive prevails everywhere. This common approach is completely different from an alternative modus operandi by designing and employing the principle of trust (see Fukayama 1995) in a trustless environment in which unknown participants are operating through a decentralized ledger technology. The basic idea behind this blockchain-inspired approach is that the use of true facts is more probable in a decentralized ledger mechanism for creating trust. Such new web applications are designed in the context of blockchain technology. This will be further outlined in Section 4.

\section{BLOCKCHAIN SYSTEMS IN URBAN PROCUREMENT AND TENDERING}

The use of blockchain systems in urban procurement and tendering may potentially have quite some advantages. These are:

- Elimination of intermediaries, so that the probability of bribery, corruption or graft can be reduced. The elimination of third parties in a tender procedure - the Achilles' heel in a procurement process - is a major benefit of urban blockchain systems; about half of the corruptions appear to be caused by the presence of intermediate (third-party) agents. In a blockchain approach, a decentralized and open ledger of records to transact value is employed, based on a peer-to-peer constellation, in which in-between trusted third parties play a role.

- Use of immutable data, so that the presence of fraud and incomplete or intermediate change in tender conditions can be diminished. Immutability of data is another major strength of the use of blockchain technology in urban tendering procedures. Information, once registered in the blockchain, cannot anymore be modified, deleted or erased. The blockchain structure signals any change in blocks data due to the sensitivity of the hash references regarding the data changes concerned. In case data changes are officially allowed, one has to rewrite all blocks that are affected by the change. The costs of this operation are usually prohibitive. Thus, blockchain systems offer a higher quality of data verification, as bid modification or change in specification may be avoided. Due to the self-automated design, there is no way to favour specific suppliers, as the bids will be encrypted.

- Transparency in blockchains, for instance, which may lead to prevention or reduction in bid rigging. In a blockchain system no intervention is possible, so that negative collaboration (e.g. hidden agreements) between unfair competitors is (almost) excluded, in particular, since any attempts to commit collaborative fraud is detected (and fined).

The above three items - in terms of their preventive capacity to cope with corruption and bribery - are concisely presented in Figure 1 (Balan, 2019). 


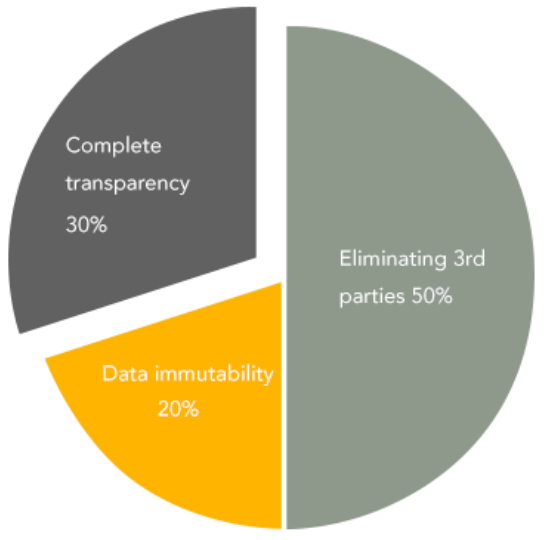

Figure 1. Overview of preventive capacity of blockchain technology for corruption.

(C) RomSoft Copyright 2019

In the next section (Section 5) we will give an illustration of a recently developed app that meets the above conditions.

\section{DESIGN OF SELF-SOVEREIGN APP (SSAPP) FOR TRANSPARENT AND ACCOUNTABLE URBAN PROCUREMENT PROCEDURES}

In the context of an European-wide project, the PrivateSky project (PrivateSky, 2020a), the notion of a self-sovereign app (SAApp) has been developed. This is a family of decentralized apps designed in the framework of the above mentioned blockchain technology (see also Balan et al., 2021). These applications (See Figure 2) function like standard web apps but are basically acting like small offline blockchains with special access rules about who can update or even delete them (Alboaie, 2019). As such, these apps are not difficult to develop or to use, even not for non-technical people (PrivateSky, 2020b). A basic feature is that the owner of data has total control on how the data are used by means of available technical methods (PrivateSky, 2020b). In contrast to normal praxis, the data are not physically saved on a server, but rather inside an encrypted folder which is anchored to the main blockchain data structure (Alboaie, 2019). Consequently, the data storage function of SSApps offers a secure system of storing and sharing data which is designed for private data management requiring high security levels.

In the specific case of urban procurement procedures, two controlling functions are needed: a Tender Offer Manager and a Bid Manager, as implemented in the WeldGalaxy platform (WeldGalaxy, 2020) for facilitating the management of tendering process for its members.

The Tender Offer Manager app (WeldGalaxy, 2020) enables the creation, visualization and sharing of a tender offer with a public or private group in a secure way. The application facilitates sharing confidential attachment documents in a secure way. The attachment can contain the documentation for tender offers or for bids created as a response to a specific tender. Depending on the situation, the tender offer can be sent anonymously, without revealing the identity of the author. This functionality applies also for the received bids which can be visualised, analysed, accepted or rejected in the same application.

The Bid Manager app (WeldGalaxy, 2020) displays all the existing tender offers for a specific sector and facilitates the creation and management of bids as response for existing open tender offers.

The transactions registered in the near chain structure in the procurement process are the submissions of tenders offers and bids. The history of transactions is kept in different offline blockchains containing the business logic, user interface of the app and anchored encrypted files.

The applications permit the work of multiple users at the same time.

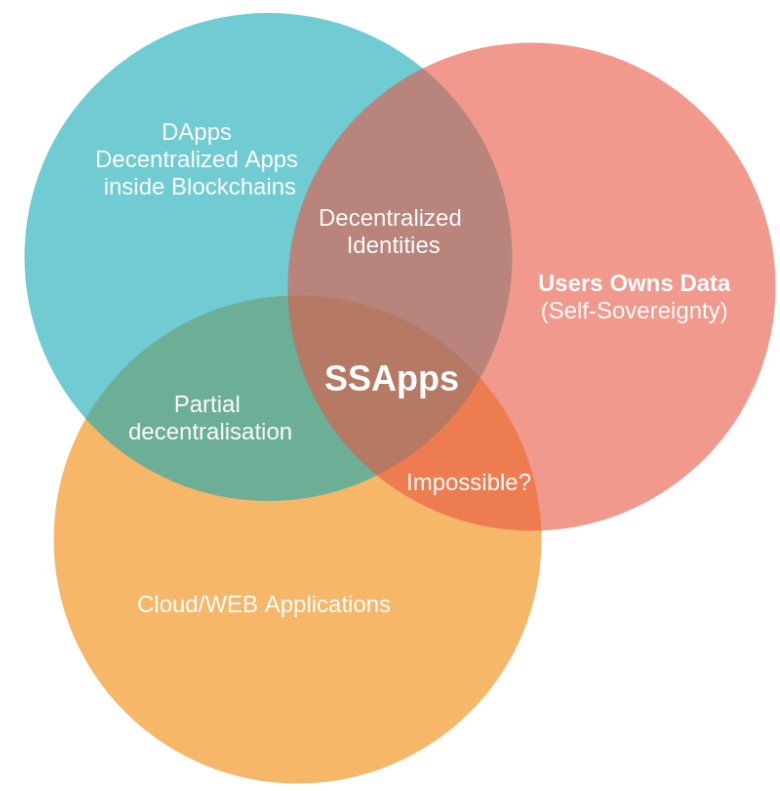

Figure 2. Positioning of SSApp concept from the open source platform PrivateSky perspective

Next, the systematic wireframes of tender offers and bids for user application and experience through the apps are presented in the Annexes. The use of the SSApps - with a cryptographic identity in the registration - may be regarded as a powerful tool against misuse in a procurement procedure (See also Table 1), in particular (see Purchasing and Procurement Center website, 2020):

- Misrepresentation (false information on the legal characteristics of a company)

- Collusion (manipulation the employees of the issuer of the bid and the bidding company)

- Falsification (false accreditations, consumer satisfaction as e.g.)

- Substitution (offering defective or lower quality products than promised in the tender offer documents)

- Price fixing (bid rigging with competitors by excluding other competitors)

- Failure to submit a tender (using false invoices approved by corrupt officials)

- Price inflation (circumvention of regular pricing procedures, e.g. by rebates to negotiators after the contract is in place). 


\begin{tabular}{|c|}
\hline $\begin{array}{l}\text { Identified scenarios that could influence } \\
\text { the procurement process and SSApps } \\
\text { benefits }\end{array}$ \\
\hline $\begin{array}{l}\text { The organization of tenders and auctions } \\
\text { requires qualified staff who know and } \\
\text { follow strict procedures. Failure to follow } \\
\text { the rules can lead to corruption or other } \\
\text { significant financial losses caused by } \\
\text { delays. }\end{array}$ \\
\hline $\begin{array}{l}\text { The organization of auctions can be } \\
\text { automated by software, reducing the risks } \\
\text { of internal attacks or delays caused by } \\
\text { non-compliance with procedures, and } \\
\text { delays in large projects or obstacles to } \\
\text { competition by attacking procedures. } \\
\text { Intrigues could be weapons through which } \\
\text { one fights the competition. Corruption of } \\
\text { the staff organizing the auctions can be } \\
\text { tempting if the stakes are millions or } \\
\text { billions of euros. } \\
\text { The fact that, in a solution that uses } \\
\text { blockchain and SSApps, there is no central } \\
\text { authority to censor or leak auction } \\
\text { information can be an important benefit. }\end{array}$ \\
\hline
\end{tabular}

In many situations there are legal requirements or internal procedures of companies that condition the purchase of goods and services by organizing auctions. People inside have a material interest in choosing the winner. A simple method of fraud is to write a specification (tender specifications) that is made with dedication for a single winner by establishing criteria that can only be met by the winner chosen before.

Blockchain data can be made indelible, traces of fraud remain, and the acts of corruption can be detected, transparency increases and the risk for counterfeiters / conspirators increases. Using smart contracts and anchoring blockchain bidding information could even allow you to check the correctness of the specifications, for example each requirement may require explanations about eligible market candidates to meet the requirements. In this way, when writing the specifications, many of the companies with compatible solutions will be able to receive automatic notifications that they are eligible to participate in tenders. In this way, the market approaches theoretical models of information availability, an aspect that conditions the existence of a real market.

If closed envelopes with the offers are not used, then the last participant could know the competition's offers.

The manipulators of the closed envelopes can clandestinely open the envelopes and can put in the offer they want the right price for winning.

\begin{tabular}{l} 
The SSAPPs solution can eliminate this \\
type of attack on the correctness of the \\
auctions because the opening of the \\
envelopes can be done cryptographically, \\
exactly at the closing of the bidding \\
period. The content of the offers \\
implemented as SSApps is immutable and \\
is anchored in the blockchain, any \\
suspicion related to the change after the \\
closing of the bidding period can be \\
eliminated. \\
The decision of the winner is made by \\
finding out the offers made by everyone. It \\
is possible for the winner to be decided \\
without opening the bids. \\
By using cryptographic techniques such as \\
homomorphic encryption in the \\
implementation of SSApps it is possible to \\
decide the winner without actually \\
decrypting all bids. Obtaining this \\
property with current methods requires \\
that a person or group of people with a \\
high moral probity respect the rules of \\
confidentiality. It would be more efficient \\
and safer if checking the compliance with \\
the auction requirements and deciding the \\
winner would be done automatically by \\
software. Especially since each interested \\
member could check (without decrypting \\
the offers) the correctness of the decision. \\
\hline
\end{tabular}

Table 1. Merits and use of the SSApps in the procurement process

The strong advantage of the use of SSApp is that the membership and identity of the bidder is unambiguously fixed through the very nature and design of the blockchain system. In this way, share is a clear and transparent constellation of identification of owner, identification of the owned object, and a one-to-one mapping of object to owner, which is based on a strong identification number and related credentials in documents that cannot be changed anymore. In order to testify the ownership, the one-to-one mapping between owners and objects, and every transfer of ownership are registered in a continuously updated ledger (See Drescher, 2017).

\section{CONCLUDING REMARKS}

Smart digital cities have to deal with complex big data. Blockchain systems may be instrumental in providing intelligent decision support to public agencies in a city. In the case of public (or private-public) tendering in an official legal procurement procedure various dimensions have to be considered, such as: the robustness of the business case development, the quality of the project brief, the public sector capacity to handle complex tendering information, the institutional organization in the city, the reliability and effectiveness of communication, the balance between streamlining and competitions, and the level of transparency in the tendering process (Liu, 2016).

The use of blockchain-inspired SSApp may be critical in ensuring that the above-mentioned concerns are adequately - or 
at least to a maximum extent - addressed. Its structure is systematic, transparent and user-friendly. It may become a useful actor-oriented tool supporting transactions in the public sector.

\section{ACKNOWLEDGEMENTS}

The authors acknowledge the technical support from PrivateSky project, co-funded from European Regional Development Fund through the Operational Program Competitiveness 2014-2020, Contract 13/01.09.2016, SMIS 106611, ID P_40_371; and WeldGalaxy project, partially funded by the European Union's Horizon 2020 research and innovation programme, grant agreement 822106 .

This work was supported by a grant of the Romanian Ministry of Research and Innovation, CNCS - UEFISCDI, project number PN-III-P4-ID-PCCF-2016-0166, within the PNCDI III" project ReGrowEU - Advancing ground-breaking research in regional growth and development theories, through a resilience approach: towards a convergent, balanced and sustainable European Union.

\section{REFERENCES}

Alboaie, S., Alboaie, L., Pritzker, Z., and Iftene, A., 2019: Secret Smart Contracts in Hierarchical Blockchains; $28^{\text {th }}$ International Conference on Information Systems Development (ISD2019 Toulon, France).

Balan, A., 2019: Is blockchain the new Dracula against corruption?, RomSoft blog, Available online: https://blog.rms.ro/index.php/2019/12/19/is-blockchain-thenew-dracula-against-corruption/

Balan, A., Alboaie, S., Kourtit, K., and Nijkamp, P., 2021: Blockchain Systems for Smart Regions, Big Data and Smart Regions (R. Laurini, eds.), Springer, Berlin.

Batty, M., 2018. Artificial Intelligence and Smart Cities, Environment \& Planning B, 45, 1, 3-6.

Drescher, D., 2017, Blockchain Basics: A Non-technical Introduction in 25 steps, Apress, DOI 10.1007/978-1-48422604-9

Fukuyama, F., 1995, Trust, Free Press, New York.

Glaeser, E., Kourtit, K., and Nijkamp, P. (eds.), 2020: Urban Empires, Routledge, London.

Komninos, N., 2014: The Age of Intelligent Cities, Routledge, London.

Komninos, N., and Kakderi, C. (eds.), 2019: Smart Cities in the Post-Algorithmic Era, Edward Elgar, Cheltenham

Korostelava, J., Mickiewicz, T., and Stepień-Baig, P., 2020, It Takes Two to Tango, Regional Studies, 54(6), 851-862.

Kourtit, K., and Nijkamp, P., 2018, Big Data Dashboards as Smart Decision Support Tools for i-Cities - An Experiment on Stockholm, Land Use Policy, 71, 24-35.

Kourtit, K., 2019: The New Urban World, Shaker, Aachen.
Kourtit, K., 2020: The Digital Urban Challenge: Intelligent Response and Smart Governance of Cities, Shaker, Aachen.

7. Liu, T., Wang, Y., Wilkinson, S., 2016: Identifying critical factors affecting the effectiveness and efficiency of tendering processes in Public-Private Partnerships (PPPs): A comparative analysis of Australia and China, International Journal of project Management, Vol. 34, Issue 4, pages 701$706 . \quad$ Available online: https://doi.org/10.1016/j.ijproman.2016.01.004

Ozdemir, A., Kourtit, K., and Nijkamp, P., 2019. Social Policy in Smart Cities, Smart Cities in the PostAlgorithmic Era (N. Komninos and C. Kakderi, eds.), Edward Elgar, Cheltenham, 235-262.

Pieroni, A., Scarpato, N., Di Nunzio, L., Fallucchi, F., and Raso, M., 2018. Smarter City: Smart Energy Grid based on Blockchain Technology, International Journal on Advanced Science Engineering Information Technology, 8 (1).

Pillay, K., Erasmus, J., 2015: Understanting corruption in tenders, Corruption watch website, https://www.corruptionwatch.org.za/wp-

content/uploads/2015/06/Corruption-Watch-Understandingtender-corruption.pdf

PrivateSky project, 2020a. Available online: https://profs.info.uaic.ro/ ads/PrivateSky/

PrivateSky, 2020b. Available online: https://privatesky.xyz/?home

Purchasing and Procurement Center, 2020: Identifying \& Avoiding Tender Fraud: 7 Fraud Types \& 4 Measures to Avoid it. Available online: https://www.purchasing-procurementcenter.com/tender-fraud.html

Ritzen, G., and Jurgensen, N., 2010. Production, Consumption, Prosumption, Journal of Consumer Culture, (13), 13-36.

Sun, J., Yan, J., and Zhang, K. Z. K., 2016. Blockchain-based sharing services: What blockchain technology can contribute to smart cities, Financial Innovation, 2(26), DOI 10.1186/s40854016-0040-y.

Transparency International the global coalition against corruption, 2020:

https://www.transparency.org/topic/detail/private_sector

WeldGalaxy. Available online: http://www.weldgalaxy.eu/

Wensink, W., Maarten de Vet, J., 2013: Identifying and reducing corruption in public procurement in the EU, Development of a methodology to estimate the direct costs of corruption and oter elements for an EU-evaluation mechanism in the area of anti-corruption, PWC report, Available online: https://ec.europa.eu/anti-

fraud/sites/antifraud/files/docs/body/identifying_reducing_corru ption_in_public_procurement_en.pdf 


\section{APPENDIX}

\section{WIREFRAMES OF TENDER OFFER MANAGER AND BID MANAGER SSAPPS}

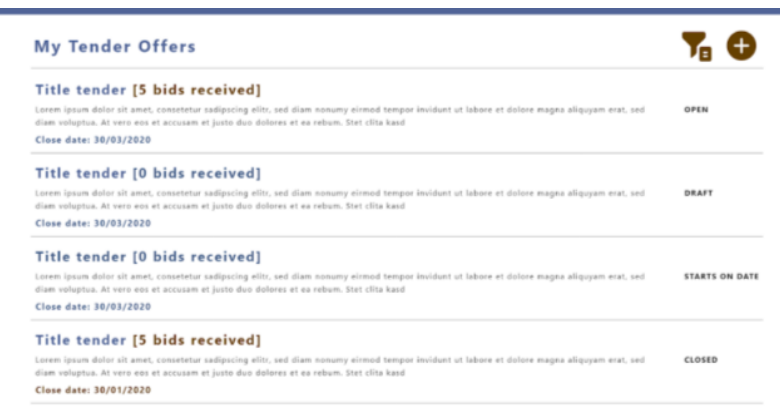

Figure A1. Tender Offer Manager SSApp - List of tender offers

The Tender Offer Manager home page displays a list of created tender offers (see Figure A1). Each tender offer in the list has a short description, a closing date and a status (open - for tender offers that were submitted with a valid closing date; closed - for tender offers that were submitted and the closing date has expired; starts on date - for tender offers that were submitted but the starting date for bidding is in the future; and draft - for tender offers which were created but not yet submitted). In the title of the tender offer one can visualise a notification message with the number of received bids for that specific tender. By clicking on the tender offer one can visualise the details and attachments of the tender and the list of the received bids and their status as in Figure A2. The search button in Figure A1 facilitates a specific filter of the tender offers based on a specific date or a keyword

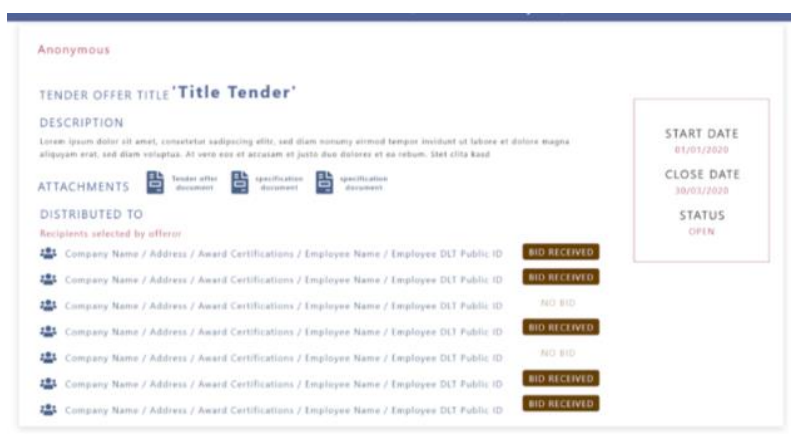

Figure A2. Details of a tender offer

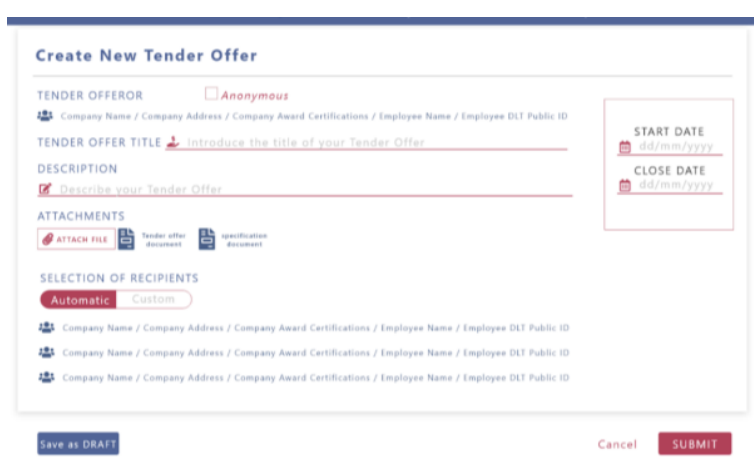

Figure A3. Creation of a new tender offer

Next, in order to create and send a new tender offer one has to click the plus button in the right up corner. Figure A3 describes the user experience for creating a tender offer. The details of the tender offeror are automatically added by the app and one can choose not to be displayed by clicking the anonymous check box. The offeror can introduce the title and a short description, choose the starting and closing dates, and make a selection of the possible bidders. The documentation of the tender offer will be than attached.

The Bid Manager displays a list of existing tender offers that are available for bidding (see Figure A4). By clicking the BID button one can make a bid for a specific tender. In the right upper corner of the home page the user has the button 'My bid', where he can visualise all the bids he made for different tenders (Figure A5). The user can visualise his bid (Figure A6) by clicking on it.

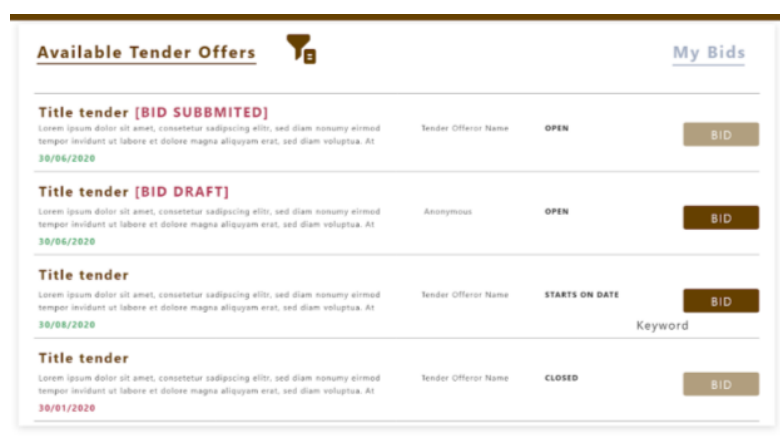

Figure A4. Available tender offers

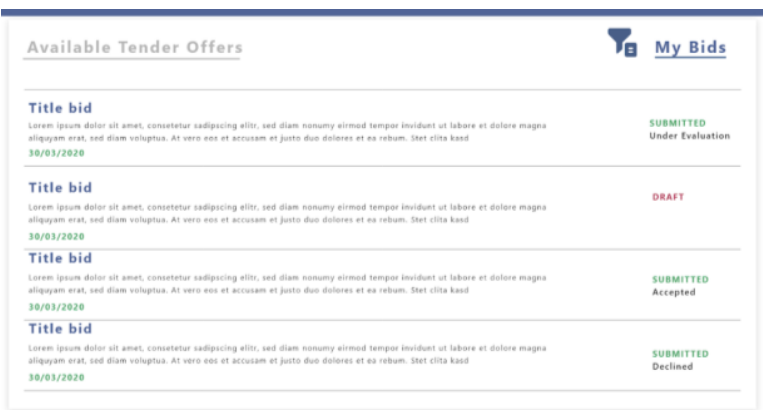

Figure A5. List of bids for a specific bidder 
The International Archives of the Photogrammetry, Remote Sensing and Spatial Information Sciences, Volume XLIV-4/W2-2020, 2020 5th International Conference on Smart Data and Smart Cities, 30 September - 2 October 2020, Nice, France

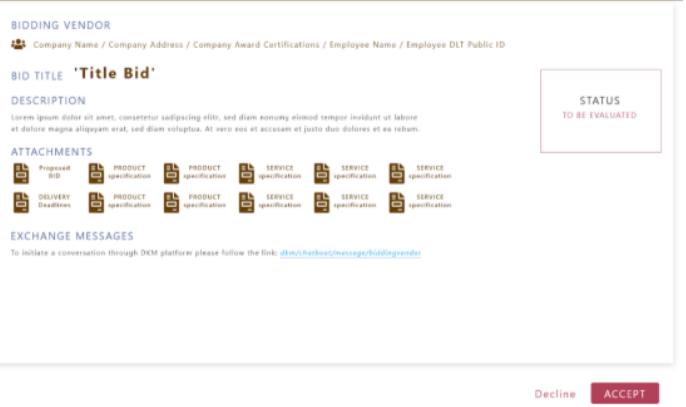

Figure A6. Summary view of a bid 